\title{
DIAGNÓSTICOS DE ENFERMAGEM DA NANDA NO PERÍODO PÓS-PARTO IMEDIATO E TARDIOa
}

\author{
Nursing Diagnosis NANDA in Puerperium at the immediate \\ and late
}

\section{Diagnósticos de enfermería NANDA durante el puerperio temprano y tardío}

\author{
Flaviana Vieira $^{1}$ \\ Maria Márcia Bachion² \\ Ana Karina Marques Salge ${ }^{3}$ \\ Denize Bouttelet Munari ${ }^{4}$
}

\section{RESUMO}

Ao retornar à comunidade, no período pós-parto, a mulher necessita de atendimento de enfermagem sistematizado. Objetivouse nesta pesquisa analisar a ocorrência de 22 diagnósticos de enfermagem de interesse no puerpério imediato e tardio. Tratase de estudo descritivo, do qual participaram 40 puérperas. Realizou-se a coleta de dados no período de fevereiro a maio de 2008, no domicílio das participantes, mediante um encontro com entrevista, exame físico e observação. 0 julgamento clínico dos diagnósticos foi baseado na Taxonomia II da NANDA. Entre os diagnósticos identificados, destacaram-se: conhecimento deficiente; risco para infecção; integridade tissular prejudicada; amamentação eficaz; ansiedade; nutrição desequilibrada, menos do que as necessidades corporais; disposição para processos familiares melhorados; risco de integridade da pele prejudicada; e insônia. Foram encontrados indícios de novos diagnósticos: risco de amamentação interrompida, risco de amamentação ineficaz. Os resultados indicam áreas para o direcionamento das ações de enfermagem no pré-natal e puerpério e a necessidade de acompanhamento mais próximo da puérpera do que o previsto nas políticas de saúde.

Palavras-chave: Diagnóstico de Enfermagem. Período Pós-parto. Enfermagem.

\begin{abstract}
By returning to the community, at the postpartum period, the woman needs systematic nursing care. The goal in this investigation was to analyze the occurring of 22 diagnosis of nursing interests into the puerperium immediate and late. In this descriptive study participated 40 puerperal. Data collecting was made during the February-May 2008 period, at the participant's residence, by a meeting, utilizing interview, physical examination and observation. The clinic judgment of the diagnoses was based in NANDA Taxonomy II. Among the diagnosis identified, have been remarked: knowledge deficit, risk for infection, impaired tissue integrity, breastfeeding effective, anxiety, altered nutrition, less than body requirements, disposition about better family processes, risk for impaired integrity skin and insomnia. Evidence has been found that suggest possible new diagnosis: risk of breastfeeding interrupted, risk of breastfeeding ineffective. The results indicate areas for the aiming of the nursing actions at pre-birth and puerperium and the accomplishment necessity nearest of the puerperal preview the politics of the health.
\end{abstract}

Key words: Nursing diagnosis. Postpartum period. Nursing

\section{Resumen}

A su regreso a la comunidad después del parto, las mujeres necesitan cuidados de enfermería de forma sistemática El objetivo de esta investigación fue analizar con qué frecuencia se presentaron 22 diagnósticos de enfermería durante las etapas de puerperio inmediato y tardío. Este es un estudio descriptivo, en el que participaron 40 madres. Los datos fueron recopilados de febrero a mayo de 2008, en el hogar de los participantes, a través de una reunión en donde se realizaron entrevistas, exámenes físicos y observación. El juicio crítico del diagnóstico está basado en la taxonomía ll de la North American Nursing Diagnosis Association (NANDA). Entre los diagnósticos identificados, destacaron los siguientes: Conocimientos deficientes, Riesgo de infección, Deterioro de la integridad tisular, Lactancia materna eficaz, Ansiedad, Desequilibrio Nutricional, Disposición para mejorar el afrontamiento familiar, Riesgo de deterioro de la integridad cutánea y Deprivación de sueño. Fueron encontrados indicios que sugieren posibles diagnósticos nuevos: Riesgo de interrupción de la lactancia materna y Riesgo de lactancia materna ineficaz. Los resultados ayudaron a identificar áreas en las que la enfermería debe enfocarse durante el período prenatal y posparto y a subrayar la necesidad de brindar una vigilancia más estrecha- de lo que está previsto en las políticas de salud - a las mujeres después del parto.

Palabras clave: Diagnóstico de enfermería. Período de posparto. Enfermería.

'Mestre, Professora Assistente da Faculdade de Enfermagem da Universidade Federal de Goiás FEN/UFG. Brasil. E-mail: flavianamori@gmail.com, ${ }^{2}$ Doutora, Professora Titular da Faculdade de Enfermagem da Universidade Federal de Goiás FEN/UFG. Brasil. E-mail: mbachion@fen.ufg.br; ${ }^{3}$ Doutora, Professora Adjunto da Faculdade de Enfermagem da Universidade Federal de Goiás FEN/UFG. Brasil. E-mail: anakarina@fen.ufg.br , ${ }^{4}$ Doutora, Professora Titular da Faculdade de Enfermagem da Universidade Federal de Goiás FEN/UFG. Brasil. E-mail: denize@fen.ufg.br 


\section{INTRODUÇÃO}

Puerpério ou período pós-parto é a fase em que ocorrem manifestações involutivas, ao estado pré-gravídico, das modificações locais e sistêmicas provocadas pela gravidez e parto. ${ }^{1}$ Didaticamente, pode ser dividido em três períodos: imediato (do $1^{\circ}$ ao $10^{\circ}$ dia após a parturição), tardio (do $11^{\circ}$ ao $45^{\circ} \mathrm{dia}$ ) e remoto (a partir do $45^{\circ} \mathrm{dia}$ ).

Nesta etapa ocorre concomitante o efetivo exercício da maternidade, na qual a mulher experimenta profundas modificações. Assim, este evento pode ser concebido como um fenômeno de âmbito tanto biológico quanto psicológico e sociocultural. ${ }^{2}$

Algumas das dificuldades "vividas" pela mulher no pósparto são relacionadas à dimensão psicossocial, refletindo não somente no seu funcionamento individual, mas nas interações que ela estabelece com o filho, o cônjuge ou outros membros da sua família. ${ }^{3}$ É importante que, no planejamento da assistência à saúde da puérpera, o profissional de saúde considere todas as informações e hábitos de vida que a mulher apresenta, assim como os conhecimentos, as experiências, tabus, crenças, hábitos e práticas culturais que são decorrentes da convivência familiar.

A assistência planejada, com a obtenção de dados e a identificação das respostas a problemas ou à etapa do ciclo de vida, de forma individualizada, considerando o contexto em que a puérpera está inserida, é fundamental nesta fase. ${ }^{4} \mathrm{~A}$ enfermagem pode contribuir significativamente quando elabora intervenções focadas nas reais necessidades da puérpera, qualificando assim o cuidado dispensado.

Os estudos com foco no puerpério têm sido realizados eminentemente no contexto hospitalar ${ }^{5-6}$ ou ambulatorial, ${ }^{7}$ configurando-se a lacuna de pesquisas que focalizem a puérpera, na perspectiva dos diagnósticos de enfermagem apresentados nesta fase, para além do ambiente dos serviços de saúde, mais precisamente no contexto comunitário.

Partindo da ideia de que, no puerpério, alguns diagnósticos de enfermagem podem ser encontrados, diretamente vinculados às especificidades deste evento no ciclo da vida, propôs-se esta pesquisa. A aplicação do Diagnóstico de Enfermagem (DE) enquanto um processo de julgamento clínico, utilizado no período de pós-parto, pode representar respostas das puérperas diante desta fase e favorecer a comunicação no sistema de referência e contrarreferência com foco na assistência integral às puérperas. Por sua vez, a análise dos diagnósticos de enfermagem no puerpério pode contribuir para a identificação de prioridades de atendimento da assistência, indicando os conteúdos essenciais a serem abordados em processos educativos e nas pesquisas na área de intervenções de enfermagem.

\section{OBJETIVO}

Esta pesquisa teve como objetivo analisar a ocorrência de 22 diagnósticos de enfermagem, de interesse no período imediato e tardio, apresentados por puérperas no contexto da comunidade.

\section{METODOLOGIA}

Estudo descritivo de abordagem quantitativa foi realizado na área de cobertura da equipe de saúde da família do Distrito Sanitário Leste de Goiânia - G0, de fevereiro a maio de 2008.

A amostra foi constituída por 40 puérperas que atenderam aos critérios de inclusão: estar no período imediato ou tardio, com criança viva, e pertencer à área de cobertura da equipe de saúde da família da região leste de Goiânia - GO, independente da escolaridade, da renda, do estado civil, do tipo de parto e da paridade. Excluíram-se as de idade inferior a dezoito anos, com presença do diagnóstico médico de transtorno cognitivo ou psiquiátrico que comprometesse a capacidade de autodeterminação.

0 estudo foi aprovado pelo Comitê de Ética em Pesquisa Médica Humana e Animal do Hospital das Clínicas da Universidade Federal de Goiás, protocolo 185/07. Mediante indicação dos agentes comunitários, as puérperas foram convidadas a participar, tendo sido esclarecidas quanto aos objetivos e procedimentos envolvidos no estudo, e aquelas que concordaram manifestaram 0 aceite por escrito, mediante assinatura do Termo de Consentimento Livre e Esclarecido.

Para a coleta de dados elaborou-se um instrumento que incluiu procedimentos de entrevista, exame físico e observação, envolvendo itens que foram estabelecidos a partir das características definidoras e fatores relacionados/fatores de risco dos diagnósticos de interesse, da Taxonomia Il da North American Nursing Diagnosis Association - Internacional (NANDA), versão 2007-2008. Estes foram selecionados a partir da revisão da literatura sobre o tema e da experiência profissional dos autores na área de enfermagem obstétrica. Para seu refinamento contou-se com três peritos.

Os DE escolhidos foram: nutrição desequilibrada, menos que as necessidades corporais; nutrição desequilibrada, mais do que as necessidades corporais; ansiedade; medo; maternidade prejudicada; risco para maternidade prejudicada; disposição para maternidade melhorada; insônia, dor aguda; amamentação eficaz; amamentação ineficaz; conhecimento deficiente, risco para infecção; integridade tissular prejudicada; risco para integridade de pele prejudicada; integridade de pele prejudicada; constipação; risco de constipação; processos familiares interrompidos e processos familiares melhorados; baixa autoestima situacional e risco para baixa autoestima situacional.

A coleta de dados foi realizada no domicilio da puérpera. 0 pesquisador responsável pelo trabalho de campo preencheu o roteiro de coleta, assinalando a inferência diagnóstica e, quando necessário, acrescentou ou modificou os termos da taxonomia da NANDA (2008), que foram destacados em itálico. Após a coleta de dados, passou-se ao processo de identificação dos Diagnósticos de Enfermagem (DE), utilizando-se o processo 
de julgamento clínico das informações obtidas. Este procedimento foi realizado por dois pesquisadores, conjuntamente. Em caso de divergências houve um processo de discussão e reflexão, até chegar-se ao consenso. Para análise dos resultados, foram utilizadas frequências simples e percentuais.

\section{RESULTADOS}

As puérperas apresentaram idade entre 18 e 35 anos escolaridade diversificada, predominando o ensino fundamental incompleto $(47,5 \%)$ e ensino médio completo $(35,0 \%)$. A maioria estava fora do mercado de trabalho formal, sendo $55,0 \%$ do lar e 22,5\% autônomas, as quais estavam envolvidas com atividades laborais informais. A raça autorreferida predominante foi a parda $(65,0 \%)$.

Em relação ao estado civil, 82,5\% encontravam-se casadas ou com união consensual. A maioria dispunha de casa própria $(60,0 \%)$, e a renda familiar foi, predominantemente, de 1 a 2 $(32,5 \%)$ ou 3 a 4 (42,5\%) salários mínimos. 0 número de pessoas que residiam no domicílio foi predominantemente de 3 a 4 (55,0\%), sendo constituído, geralmente, pela puérpera, o companheiro, um ou dois filhos.

As puérperas tiveram predominantemente parto cesáreo $(65,0 \%)$, de criança a termo $(90,0 \%)$; a maioria tinha até dois filhos (70,0\%), sendo que $37,5 \%$ referiram gravidez planejada. Buscaram predominantemente o pré-natal no primeiro trimestre de gestação $(80,0 \%)$, sendo que $62,5 \%$ fizeram no mínimo seis consultas.

Quanto aos diagnósticos investigados, conforme mostra a Tabela 1, o conhecimento deficiente apresentou-se em $100 \%$ das puérperas, envolvendo diferentes tópicos: armazenamento do leite materno (97,5\%); cuidados prestados a sua criança (90\%); ordenha do leite materno (87,5\%); amamentação (85\%); alimentação materna no pós-parto (75\%); cuidados com as mamas (45\%); cuidados com incisão cirúrgica abdominal ou perineal ou laceração (10\%). 0 fator relacionado para este diagnóstico esteve ligado à falta de exposição à informação profissional e fator cultural. As participantes alegaram não terem recebido orientações sobre estes assuntos no pré-natal ou que receberam informações superficiais.

Previamente ao conhecimento do armazenamento do leite materno, é necessário o conhecimento sobre ordenha das mamas. Quando este conhecimento se fez presente, na maioria das vezes, foi parcial ou errôneo, com o uso de "bombinha" para a ordenha, expressão somente do mamilo e uso de calor úmido antes do procedimento.

Identificou-se que $97,5 \%$ das puérperas apresentaram um possível diagnóstico de enfermagem, o de risco de amamentação interrompida, tendo como fatores de risco a falta de conhecimento sobre armazenamento do leite materno, falta de conhecimento com relação à ordenha e o emprego materno.
Apesar de a maioria das puérperas no momento da investigação apresentar amamentação eficaz (87,5\%), estas relataram fatores que poderiam levar a amamentação ineficaz, configurando uma situação interpretada como outro possível diagnóstico de enfermagem de risco para amamentação ineficaz, em 30 puérperas $(75,0 \%)$.

Os fatores de risco que mais se destacaram nos casos deste possível diagnóstico foram déficit de conhecimento sobre amamentação e fatores culturais, que acarretaram comportamentos inapropriados, como oferecer chupeta à criança, chá para tratar cólica e/ou icterícia e uso de mamadeira para dar o chá, considerando-se as diretrizes para a manutenção da amamentação. Muitas puérperas consideraram ser necessário aleitamento materno exclusivo até o $6^{\circ}$ mês de vida e, embora fizessem uso de chá, não o classificavam como um alimento complementar. 0 risco para amamentação ineficaz pode levar à quebra da continuidade do processo de amamentação, consequentemente à amamentação interrompida, e se este não for resolvido, pode surgir o desmame.

A amamentação ineficaz foi verificada em 12,5\% das participantes, estando também relacionada a conhecimento deficiente.

Dentre as puérperas avaliadas, 92,5\% apresentaram risco para infecção, localizado nas seguintes regiões topográficas: mamas, vagina, pele, abdome e períneo.

A integridade tissular prejudicada esteve presente em 90,0\% das puérperas, relacionada principalmente aos fatores mecânicos (100,0\%), como a incisão cirúrgica de parto cesáreo ou de episiotomia/episiorrafia.

Mais da metade das puérperas $(57,5 \%)$ apresentou risco para integridade da pele prejudicada, tendo como fatores de risco predominantes: nutrição desequilibrada, menos do que as necessidades corporais; uso de substâncias químicas (uso repetido de sabão) nas mamas e presença de pele úmida (mamilos ou mamas úmidas).

0 prejuízo à integridade da pele foi identificado em $40 \%$ das puérperas. No caso das mamas, foi devido ao uso de sabão e/ou posição incorreta para amamentar, e, nas incisões cirúrgicas, de parto normal ou cesáreo, as feridas não estavam completamente cicatrizadas.

Além das modificações biológicas, neste período ocorrem também as modificações e adaptações psicossociais que podem gerar ansiedade, verificada em $80 \%$ das puérperas. Foi marcante a fala das participantes relativa a um temor vago e impreciso de que "algo de ruim" poderia acontecer com a criança.

Das puérperas investigadas, 72,5\% apresentaram nutrição desequilibrada, menos do que as necessidades corporais, relacionada predominantemente ao fator cultural, seguida pelos fatores psicológicos e econômicos. No pós-parto, a alimentação materna foi modificada em função de conselhos dados por membros da família, em especial de mulheres que já vivenciaram o puerpério. Estes levaram à adoção de 
comportamentos inapropriados, como restrição de alimentos, entre eles carne de porco, peixe, couve, frutas cítricas, feijão, arroz, ou substituições de grandes refeições por sopas, canjicas.

Apenas duas puérperas (5\%) apresentaram nutrição alterada para mais do que as necessidades corporais, por influência também do fator cultural. Uma das puérperas tinha um consumo excessivo de canjica, sob orientação da mãe, com a finalidade de aumentar a produção de leite materno, e um consumo hiperlipídico, com uma frequência diária de frituras na composição da alimentação; no outro caso, a puérpera alimentava-se por estímulos internos: ansiedade, irritabilidade, tristeza, preocupação.

Observou-se que 47,5\% das puérperas tiveram risco de constipação, devido à ingestão insuficiente de fibras e de líquidos. 0 diagnóstico constipação esteve presente em 45\% das puérperas, relacionado principalmente a ingestão insuficiente de fibras e de líquidos.

A dor aguda apresentou-se em 47,5\% das puérperas, tendo como fatores relacionados agentes lesivos biológicos, entre eles: incisão cirúrgica por parto cesáreo ou episiotomia no parto normal, e/ou posição inadequada durante a amamentação. Outro fator foi o agente lesivo químico (uso do sabão com frequência na higienização das mamas).

0 período pós-parto leva a modificações no arranjo familiar, que, nestas puérperas, significou movimento de apoio, contribuindo para o diagnóstico de disposição para processos familiares melhorados em $60 \%$.

No entanto, $40 \%$ das famílias apresentaram o diagnóstico de processos familiares interrompidos, por enfrentarem crises situacionais, devido à própria transição representada pelo período, ou outras questões que existiam anteriormente, não vinculadas especificamente ao puerpério.

Insônia foi identificada em 52,5\% e esteve relacionada predominantemente ao fato de acordar mais vezes durante a noite para cuidar e amamentar a criança.

Observou-se que uma parte considerável apresentou disposição para a maternidade melhorada $(47,5 \%)$. No entanto, 32,5\% das puérperas apresentaram risco para maternidade prejudicada, relacionada predominantemente a fatores sociais, tais como: nível socioeconômico baixo, gravidez não planejada e dificuldades financeiras. Dentre os fatores psicológicos destacou-se o distúrbio do sono.

A maternidade prejudicada foi evidenciada em $20 \%$ das puérperas, caracterizada principalmente por habilidades pobres ou impróprias para o cuidado com a criança por parte destas mulheres; um exemplo foi o uso de lenço umedecido de modo exclusivo para higienização da região perineal e genital, em vez da higiene com água e sabão, levando a lesões hiperemiadas e descamativas nestas regiões.

A baixa autoestima foi evidenciada em $30 \%$ das puérperas, relacionada à falta de reconhecimento do companheiro e distúrbio na imagem. 0 risco de baixa autoestima apresentou-se em 17,5\% das puérperas.
Outro diagnóstico relacionado com a adaptação, principalmente psicossocial, foi o medo, que estava presente em 27,5\% das puérperas, relacionado à falta de familiaridade com a maternidade, principalmente nas primíparas, e por separação do sistema de apoio em situação potencialmente estressante.

\section{DISCUSSÃO}

Pode-se caracterizar a amostra como de puérperas de baixa escolaridade e renda, com companheiro estável, casa própria e atividades relacionadas ao cuidado do próprio lar.

Quanto à caracterização obstétrica, o elevado índice de parto cesáreo reflete a realidade do município, que é um dos campeões em índice de cesárea no Brasil. Segundo os dados mais atuais disponíveis, em 2005, no sistema público de saúde do Brasil, a taxa de cesárea foi de 43,3\%, e a de Goiânia de $61,3 \% .{ }^{8}$ Segundo informações obtidas na Secretaria Municipal de Saúde, em Goiânia, este percentual foi de 62,6\% em 2006. 0 Rio de Janeiro também apresentou taxas elevadas de parto cesáreo, $32,1 \%$ na rede pública e $83,2 \%$ na rede privada. ${ }^{9}$ Esta taxa sobrepõe de forma alarmante a preconizada pela Organização Mundial de Saúde (OMS), que recomenda, desde 1985, que o índice de cesárea não ultrapasse 15\% em qualquer país. $^{10}$

Uma das possibilidades que contribuiria para redução destes índices é o maior investimento no Programa de Humanização no Pré-natal e Nascimento que, dentre várias propostas, incentiva um papel mais ativo das mulheres no seu processo de parturição e uma assistência baseada na evidência científica para que procedimentos invasivos não sejam realizados desnecessariamente. ${ }^{2}$

Em relação ao número de filhos, os resultados apresentados na amostra denotam semelhança deste grupo com a tendência da população em geral, que no ano de 2000 apresentou média de 2,39 filhos por mulher, segundo dados do censo demográfico. ${ }^{11}$

A abordagem dos profissionais que atenderam estas mulheres no pré-natal parece não ter desenvolvido um processo satisfatório de orientação para o puerpério. 0 tópico relacionado ao armazenamento do leite materno esteve relegado no preparo pré-natal. Aliado ao fato de que este tema geralmente não faz parte do senso comum, isto pode contribuir para que elas não tenham condições de armazenar seu leite de forma adequada e segura. Estudo recente sobre aconselhamento para lactação mostrou que somente $16,7 \%$ das puérperas sabiam explicar deles, levando em conta os fatores relacionados/fatores de risco e caracter, com 83,3\%. sobre o armazenamento. ${ }^{12}$ Este desconhecimento pode favorecer o desmame precoce, nos casos em que a puérpera esteja inserida no mercado de trabalho e precise ausentar-se do domicílio.

Um estudo mostrou que 1/3 das crianças de até três meses de idade já não eram amamentadas. Um dos motivos encontrados foi o afastamento do binômio mãe-filho devido ao 
retorno da puérpera ao emprego. ${ }^{12}$ Neste sentido, a falta de conhecimento sobre ordenha pode levar a complicações na mama, como o ingurgitamento mamário, devido a não expressão do leite ingurgitado, o que, consequentemente, acarreta traumas mamilares e até mesmo mastites.

Práticas como oferecimento de chá, mamadeira, chupeta e outros cuidados com o coto umbilical (óleo de azeite, "óleo de pau", faixa abdominal) que não os recomendados na alta hospitalar (higienização com água e sabão e álcool a 70\%) foram verificados entre as participantes, em função de práticas vinculas ao contexto cultural. Silva, Christoffel, Castro e Ribeiro ${ }^{13}$ sinalizam que, de acordo com as culturas, há maneiras de cuidados com a criança específicos, geralmente crenças e práticas de avós e/ou mães que são herdados e repassados para filhas e netas. Este universo cultural geralmente é pouco investigado pelos profissionais de saúde.

Na higienização das mamas, muitas mulheres utilizavam sabão, o que é contraindicado, uma vez que o próprio corpo humano reduz sensivelmente o número de bactérias dos mamilos, desde que sua ação não tenha interferências por agentes externos. 0 uso de sabão pode prejudicar a integridade e resistência da pele..$^{14}$

Percebe-se que as puérperas, no período imediato e tardio, foram influenciadas pelas crenças e hábitos da família. A falta de informações profissionais recebidas remete a reflexões sobre a atuação da enfermagem no pré-natal e no período puerperal. A presença de conhecimentos essenciais poderia apoiar a puérpera a enfrentar esta fase da vida com mais segurança.

Evidenciou-se a necessidade de um processo educativo participativo, progressivo e planejado no pré-natal e puerpério, para que as crianças possam receber o leite materno de forma exclusiva, no período adequado. Se não houver uma intervenção no tempo necessário, o diagnóstico de risco de amamentação ineficaz pode se tornar real, o que pode acelerar o desmame.

0 diagnóstico de integridade da pele prejudicada pode refletir diretamente na ocorrência de outros diagnósticos, entre eles o de risco de amamentação ineficaz ou risco de amamentação interrompida e o de dor aguda, o que pode comprometer não somente a amamentação, mas também a satisfação da puérpera com o período de pós-parto. Mamilos muito dolorosos e machucados, não são normais, embora frequentes. ${ }^{15}$

Por estar em uma fase de transição, de readaptação da sua vida e da família, em maturação de uma nova identidade: a de mãe, com novas responsabilidades para com o cuidado com o filho, a puérpera pode apresentar respostas como a ansiedade. ${ }^{16}$

Por outro lado, o nascimento da criança pode favorecer um bom funcionamento da família. É nela que as puérperas encontram maior apoio, buscam conhecimento sobre a forma de vivenciar o pós-parto, apoio emocional e financeiro. Com isso a familia pode tanto favorecer o enfrentamento do período pósparto quanto interferir negativamente nesta fase. ${ }^{13}$
Um fenômeno evidentemente influenciado pela cultura familiar é a nutrição. As puérperas seguiam restrições alimentares (arroz, feijão, carne de porco e de peixe, couve, repolho, pepino, carne assada, massas, frutas cítricas, refrigerantes, chocolates, pimenta, pimentão, derivados de leite, entre outras) ou substituíam as grandes refeições por canjica ou sopas, pois acreditavam que alguns alimentos poderiam Ihes fazer mal e/ou às crianças. Aconselhadas por suas mães, irmãs, avós e companheiros, se apoiavam principalmente na figura feminina que já haviam vivenciado o pós-parto. Estudo recente ${ }^{7}$ aponta uma queda acentuada no consumo de quase todos os alimentos e nutrientes no pós-parto, sendo que $40 \%$ das puérperas restringiram o consumo em mais de $40 \%$.

0 incentivo a uma alimentação adequada deve acontecer desde o pré-natal e deve ser reforçado no pós-parto, uma vez que a nutrição desequilibrada pode ter consequências no organismo da puérpera, sendo uma delas a constipação. Um estudo ${ }^{17}$ encontrou frequência aumentada de constipação $(41,3 \%)$ no puerpério, quando comparada aos trimestres gestacionais. Descreveu, ainda, que a constipação é um sintoma gastrointestinal esperado tanto na gravidez quanto no puerpério; na gravidez, devido à ação da progesterona e diminuição da motilidade do trato gastrointestinal, e, no pósparto, devido à presença de hemorroidas e/ou dor ocasionada pela cicatriz perineal.

A ocorrência de dor no período pós-parto devida às modificações fisiológicas ou intercorrências, como traumas mamilares, incisões cirúrgicas por parto cesáreo, lacerações ou episiotomias no parto normal e ainda problemas relacionados a amamentação, como o ingurgitamento, traumas mamilares e técnica incorreta de amamentação, também foi observada em outros estudos. ${ }^{3,14-15}$

Além da dor, outros diagnósticos, como a insônia, podem interferir na recuperação da puérpera e comprometer 0 desenvolvimento do papel de mãe. ${ }^{6}$ As puérperas referiram que gostariam de dormir mais para estarem descansadas para cuidar da criança durante o dia. A insônia pode estar associada a outros diagnósticos, como risco de maternidade prejudicada, ansiedade e medo.

0 apoio na fase de transição do puerpério é recebido, principalmente, da família que ajuda nos afazeres da casa e no cuidado com a criança. As puérperas com risco de prejuízo à maternidade precisam de maior apoio, tanto familiar quanto social, pois algum fator mais estressante pode modificar a condição de risco para real. ${ }^{18}$

A baixa autoestima no puerpério esteve ligada ao comportamento dos companheiros/parceiros. As puérperas se sentiam desamparadas, relataram a importância do apoio e reconhecimento deles nesta fase que consideraram ser importante na vida delas e das crianças. Este fenômeno deve ser avaliado durante o pré-natal, assim como deve ser investigada a rede de suporte social, para que na fase de pósparto a puérpera tenha o apoio necessário e disponível para 
Diagnósticos de enfermagem da NANDA

Vieira F, Bachion MM, Salge AKM, Munari DB

enfrentar as mudanças e necessidades nesta etapa da sua vida. ${ }^{18}$

0 que pode favorecer o enfrentamento do medo pela puérpera é o apoio encontrado na família, o contexto social e cultural que está inserida. Outra questão importante é o suporte profissional, que pode aliviar o medo que ela enfrenta relacionado à sua saúde, e principalmente a da criança.

\section{CONCLUSÃO}

Tendo como base o objetivo de analisar a ocorrência de 22 diagnósticos de enfermagem de interesse nos períodos imediato e tardio, apresentados por puérperas no contexto da comunidade, identificaram-se neste estudo:

- diagnósticos reais - conhecimento deficiente; integridade tissular prejudicada; ansiedade; medo; insônia; nutrição desequilibrada: menos do que as necessidades corporais; nutrição desequilibrada: mais do que as necessidades corporais; amamentação ineficaz; maternidade prejudicada; processos familiares interrompidos; dor aguda; constipação; integridade da pele prejudicada; baixa autoestima situacional;

- diagnósticos de risco - risco de infecção; risco de integridade da pele prejudicada; risco de maternidade prejudicada; risco de baixa autoestima situacional; risco de constipação;

- possíveis novos diagnósticos de risco - risco de amamentação interrompida; risco de amamentação ineficaz;

- diagnósticos de bem-estar - amamentação eficaz; disposição para processos familiares melhorados; disposição para maternidade melhorada.

Percebe-se, de um lado, o movimento das puérperas e de sua família para alcançar um nível maior de bem-estar, no aleitamento, no exercício da maternidade e nos processos familiares. De outro, as puérperas convivem com fatores que as colocam em situação de suscetibilidade a eventos negativos para a saúde do binômio mãe-filho. Somam-se a este contexto as respostas que denotam problemas de saúde já instalados. Isto quer dizer que elas convivem com aspectos positivos, negativos e de risco no continuum bem-estar/alterações da saúde.

Este quadro indica a necessidade de uma reflexão profunda acerca da responsabilidade da enfermagem sobre sua atuação tanto no puerpério como no pré-natal e sugere que é preciso acompanhamento mais próximo destas puérperas, adotandose uma abordagem individualizada e específica de enfermagem.

0 Ministério da Saúde ${ }^{2}$ preconiza que a puérpera seja avaliada, na unidade mais próxima do seu domicílio, entre $07^{\circ}$ e o $10^{\circ} \mathrm{dia}$, para a denominada revisão puerperal precoce, e retorne até $042^{\circ}$ dia para a revisão puerperal tardia. Embora esta instância traga fortemente o discurso da humanização do atendimento, a abordagem apresentada ainda privilegia os aspectos biológicos, enquanto os aspectos psicossociais são abordados de forma muito tênue.
Esc Anna Nery Rev Enferm 2010 jan-mar; 14 (1): 83-89

A Enfermagem pode e precisa contribuir de forma mais decisiva para os resultados de saúde da população. Tomando como base este mapeamento de diagnósticos de enfermagem, poderia ser criado um protocolo de avaliação das puérperas que fosse mais coerente com a especificidade da profissão e desse mais visibilidade para o agir da enfermagem, e, principalmente, que possibilitasse atuação mais assertiva, de acordo com as reais necessidades deste grupo de usuárias do Sistema Único de Saúde.

Deveria fazer parte de toda formação do profissional de enfermagem, independente de ser especialista ou não, a substituição da abordagem atual, que ainda prevalece fragmentada, biologicista e hospitalocêntrica, por uma visão integral da puérpera no seu contexto sociocultural e familiar.

\section{REFERÊNCIAS}

1. Rezende J. Obstetrícia. $10^{\mathrm{a}}$ ed. Rio de Janeiro (RJ): Guanabara Koogan; 2005.

2. Ministério da Saúde (BR). Parto, aborto e puerpério: assistência humanizada à mulher. Brasilia (DF); 2001.

3. Afonso E. Dificuldades da mulher no puerpério: subsídios para a enfermagem. [dissertação de mestrado]. Lisboa (PO): Universidade Católica Portuguesa; 1998.

4. Pereira SVM, Bachion MM. Diagnósticos de enfermagem identificados em gestantes durante o pré-natal. Rev Bras Enferm 2005; 58 (6): 659-64.

5. Mascarenhas D, Cruz ICF. Aconselhamento para lactação na Unidade de Terapia Intensiva Neonatal: estudo descritivo. Online Braz I Nurs [on-line] 2006 abr; [citado 10 maio 2008] 5 (2): 289-94. Disponivel em: http://www.portalbvsenf.eerp.usp.br/scielo.php.

6. Abrão ACFV, Gutiérrez MGR, Marin HF. Utilização do diagnóstico de enfermagem segundo a classificação da NANDA, para a sistematização da assistência de enfermagem em aleitamento materno. Rev Latinoam Enfermagem [on-line] 1997 abr; [citado 09 jul 2007] 5 (2):4959. Disponivel em: http://www.scielo.br/pdf/rlae/v5n2/v5n2a07.pdf. 7. Castro MBT, Kac G, Sichieri R. Padrão de consumo alimentar em mulheres no pós-parto atendidas em um centro municipal de saúde do Rio de Janeiro, Brasil. Cad Saude Publica. [on-line] 2006 jun; [citado 2008 set 04] 22(6): 1159-70. Disponivel em: http:// www.scielo.br/pdf/csp/v22n6/05.pdf.

8. Ministério da Saúde. (BR) DATASUS. Informações de saude. Cadernos de Informações de Saúde [on-line] 2007 jul; [citado 25 maio 2008]. Disponivel em: http://tabnet.datasus.gov.br/tabdata/cadernos/ cadernosmap.htm.

9. Knupp VMAO, Melo ECP, Oliveira RB. Distribuição do parto vaginal e da cesariana no município do Rio de Janeiro no período de 2001 a 2004. Esc Anna Nery Rev Enferm 2008 mar; 12 (1): 39-44.

10. World Health Organization-WHO. Appropriate technology for birth. Lancet 1985; 2: 436-37.

11 Fundação Instituo Brasileiro de Geografia e Estatística-IBGE. Censo Demográfico: Brasil, 2000. [on-line] [citado 11 maio 2008]. Disponivel em: http://www.ibge.gov.br/home/estatistica/populacao/censo2000. 
12. Mascarenhas MLW, Albernaz EP, Silva MB, Silveira RB. Prevalence of exclusive breastfeeding and its determiners in the first 3 months of life in the south of Brazil. J Pediatr 2006; 82 (4): 289-94.

13. Silva LR, Christoffel MM, Castro SJ, Ribeiro F. A prática do cuidado prestado pelas mulheres aos filhos no domícilio. Enferm Global. [online] 2007 maio; (10): [citado 14 set 2007] 1-9. Disponivel em: http:/ /www.um.es/ojs/index.php/eglobal/article/viewFile/207/244.

14 Secretaria Municipal de Saúde- SMS (RP). Núcleo de Aleitamento Materno- NALMA/ EERP-USP/ Programa aleitamento materno. Manual de procedimentos: prevenção e tratamento das intercorrências mamárias na amamentação. Ribeirão Preto, 1998; [citado 12 jul 2007]. Disponivel em: http://arcamposeliseos.pmrp.com.br/ssaude/ programas/ALEITA/Apostila.pdf.
15. Giugliani ERJ. Problemas comuns na lactação e seu manejo. J Pediatr 2004; 80 (5): 147-54.

16. Faisal-Cury A, Menezes PR. Ansiedade no puerpério: prevalência e fatores de risco. Rev Bras Ginecol Obstetr 2006; 28 (3): 171-78.

17. Herrero BT, Martínez MR, Plaza ML, Gutiérrez RL, García P, García ARF, et al. Signos y síntomas gastrointestinales durante el embarazo y puerperio en una muestra de mujeres españolas. Atencíon primaria. [on-line] 2001 jun; 28 (1): [citado 07 ago 2007] 53-8. Disponivel em: http://www.doyma.es/cgiin/wdbcgi.exe/doyma/mrevista.

18. Zagonel IPS, Martins M; Pereira KF, Athayde J. 0 cuidado humano diante da transição ao papel materno: vivências no puerpério. Rev Eletr Enferm [on-line] 2003; [citado 29 jul 2007] 5 (2): 24-32. Disponivel em: http://www.revistas.ufg.br/index.php/fen.

\section{NOTA}

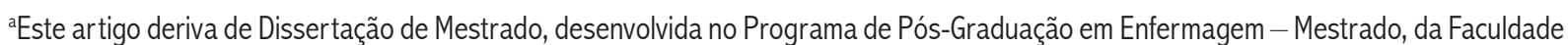
de Enfermagem da Universidade Federal de Goiás (FEN/UFG). 